out that wool and silk become positively charged on rubbing, but polyvinyl chloride fibres ('Rhovyl') become negatively charged. A blend of 25 per cent polyvinyl chloride fibre and 75 per cent wool takes on no charge at all. Prof. Darmois outlined his theory of these effects.

The chairman, Mr. J. Wilson, summed up the symposium. He observed that a wide range of topics had been covered, some of which are individually worth a complete meeting for themselves, having regard to the large amount of work which is going on and to the vigorous discussions which were held, particularly on the subjects of crystallinity and the relationship between fibre and fabric properties.

\section{THE WORKER IN INDUSTRY}

$\mathrm{I}^{\mathrm{N}}$

TRODUCING a joint paper presented to the annual conference of the British Institute of Management at Harrogate in 1953, K. H. F. Murrell, director of the ergonomics department of Tube Investments, Ltd., stated that the main contribution of the psychologist to industry would be in studying the effect of bad equipment design on the health and efficiency of workers on a long-term basis. This would include such factors as the posture, either seated or standing, which the equipment imposes on the worker, and which may follow either from the shape of the equipment or from the design of its controls; the actual methods by which work is done, such as the application of force in an unnatural position; and the conditions of heat or noise tnder which he has to work. Much of industry works below maximum efficiency because it has, through neglect of physiological principles, partly 'worn-out' its working force. The most important contribution of the psychologist might be summed up as attempting to answer various aspects of the question "What makes people behave as they do when confronted with a given situation and what can be done about it ?" Some of these aspects might be: What is a real incentive for people to work? Why do people resist change ? Is there such a thing as fatigue in repetitive work or is it merely monotony or boredom? What is the nature of skill in a particular task and how can it best be acquired?

To be effective the research worker must be familiar with the worker on the job and, from his own experience, Murrell gave examples to show how good theoretical research had been ineffective because it had failed to take account of the actual work situation.

A. T. Welford, director of the Nuffield Unit for Research into Problems of Ageing in the University of Cambridge, described a closely connected series of studies on some problems of speed in human performance. Men of different ages from the twenties to the seventies were set to work at a task where they had to plot positions on a grid by moving a pointer. The older men were on average substantially slower than the younger, but the slowness was not due to slowness in moving the pointer; it was rather due to more careful and meticulous placing of it.

The same results appeared in several other tasks ; an experiment was accordingly devised in which careful measurements were made of reaction times and movement times under conditions where they could be separated with certainty. A man doing a task sat in front of a panel of four lights. One of these came on and the operator had to move a lever in the corresponding direction as quickly as possible from a central point to an end stop and back again. As soon as he got back to the centre another light came on, and so on. When the results were examined it was found that the actual time moving did not increase but tended to fall with age. The time elapsing between a light appearing and the man beginning to move the lever did increase significantly. A further point with this was noticed, in that the oldest men, in their sixties, tended to fall slightly at the end stop. The older men appeared to be having difficulty in welding the out and back movements into a single whole. These experiments link with a number of other results to suggest an important general principle, namely, that it is the time taken over stationary portions of a manipulative task which are more deserving of attention. These tend to increase with certain types of fatigue.

Evidence would seem to be accumulating that it is not correct to think of a manipulative operation as consisting merely of a series of movements. It consists rather of a series of acts of perception either by the eyes or by touch or by sound which have to be translated into movement. It is the perception and translation by the central media of the brain which are the important components of the operation, and it is in terms of these that operators must be analysed for work study purposes if general results are to be obtained which apply more widely than to each individual operation studied.

Welford also said that, while relatively little interest has been shown by psychologists in training the industrial worker, there is great scope for further co-operation between experimenters and industry. One example of a study with important practical implications was the one carried out about four years ago by G. B. Gibbs, of the Medical Research Council. Gibbs studied the performances of men on a machine where the display-control relationships could be made easier or more difficult. He divided the men into two groups of equal ability and trained one, first on a relatively easy task, and then transferred them to one which was similar but in which the displaycontrol relationships were more difficult. The other group were trained on the same two tasks but in the reverse order. The results showed clearly that the second group, after being trained on the difficult task, came to the easy one and performed it much better than they would have done if they had not had the previous difficult training. With the other group Gibbs found that the previous training on one easy task made no difference to their ability to perform the more difficult one.

Dr. H. D. Darcus, of the Climatic and Working Efficiency Unit of the Medical Research Council, stated that one of the possible approaches to the study of the activity of man at his work is to find out under what conditions the man may be allowed to work at his greatest physiological efficiency. Emphasis should be placed on the output of the man rather than the effort the man has to put in to achieve that output. This is probably acceptable in most work situations because the operator is only using a small proportion of his total capacity and he can be expected to do a little bit more without suffering physical harm. The load to which a man is subjected should be kept as low as possible to give him a reserve of effort, a reserve capacity. If 
that is done the problem of reduced capacity due to extremes of environmental conditions, hot climates, or due to disabilities or age, is not quite so acute because the load on the individuals working under those conditions or on the aged or disabled worker is still below their level of output.

What is the maximum capacity of the body for exercise ? One approach has attempted to work out an endurance or tolerance limit, usually about 50 per cent of maximum capacity. When a person starts to work, physiological changes occur in the body, and these changes increase until a balance is struck between the energy he is putting out and his external work. He will go on using the same amount of energy for the same amount of external work, although not many people work at a steady rate. The endurance limit can be increased by training the individual to become physically fitter by acclimatization. One way to push the endurance limit up is to bring the load down, thereby reducing the effort to gain a given output. This endurance-level will fall with age, with certain disabilities and under extremes of temperature, and the safety level will become less and less.

This endurance limit is the maximum level at which a man can be expected to work over a period of time. During a long period of work, the energy output remains constant initially; but as time passes it is necessary to put out more energy because the efficiency of the muscles doing the job is becoming less and more muscles have to be used to produce the same result; more muscles demand more energy and the safety margin of effort becomes reduced. Provided this safety margin is not exceeded, the operator is paying as he goes ; that is, he is getting sufficient oxygen to allow the energy for the muscles he is using. If this level of effort is exceeded, he no longer gets enough oxygen for his energy requirements. This condition can be maintained for a time ; but the longer it goes on the bigger becomes the physiological debt. Another aspect of this is the use of rest pauses. In Great Britain it is usual to have a break in which the operators probably sit down. In Sweden, if work of a very cramped nature, such as sewing, tabulating or assembly, is being undertaken, they sometimes have Swedish drill, which is rather like organized ballet.

There is no one physiological method which will give an overall picture of man at work in all circumstances. If it is desired to use physiological methods for different measurements, the methods to be used for particular situations must be very carefully chosen, the results carefully integrated and finally interpreted with the utmost caution. The main difficulty at the present time is that these methods are mainly designed to investigate man working under extreme conditions, and these situations are very rare in industry.

The experimental approach is the one which will produce the best results, involving as it does formal scientific methods under controlled conditions. The first thing to do is to find out exactly what the problem is and then determine the main factors within that problem. One way of dealing with it is for research people to go out into industry with the industrialist to examine the problem and see if it really warrants research or if it can be dealt with by some other means. What is necessary is encouragement from industry itself, not so much on ad hoc problems, but for establishment of a long-term policy.

\section{PROBLEMS OF AIRCRAFT NOISE}

TN reply to a question in the House of Commons 1 on June 28, regarding progress in research by the Ministry of Supply into the silencing of aircraft engines, Mr. Duncan Sandys stated that work in this field is also being carried out by the Ministry of Transport and Civil Aviation and by universities and aircraft firms on their own initiative. In a detailed statement circulated in the Official Report, expenditure by the Ministry of Supply on this problem in the current year is given as $£ 100,000$ compared with $£ 40,000$ last year, and the Ministry of Transport and Civil Aviation is also expected to spend about $£ 20,000$.

The problem of reducing aircraft noise is being tackled from several angles. The main effort has been concentrated on jet engines. An extensive programme being carried out by a leading firm of engine makers, under contract by the Ministry of Supply, includes a detailed analysis of the noise of a jet engine operated with various alternative types of nozzle on an openair test bed. The nozzles which are being tested include toothed, corrugated, convergent-divergent and fish-tail types. Promising results have been obtained from toothed and corrugated nozzles, and further studies are being made to decide the optimum shapes for these types. A special study of the by-pass engines in relation to the noise problem is being carried out, with the object of determining the relationship between noise, jet velocity and temperature. 'The effect on noise of injecting water into the jet stream is also being investigated.

Two other engine companies are working under Ministry of Supply contract on silencers for piston engines used in helicopters. The Ministry of Transport and Civil Aviation is experimenting with the construction of a brick baffle-wall at Iondon Airport. This wall is shaped to accommodate the forward part of a large civil aircraft, with the object of reducing noise in certain directions when the engines are being run on the ground. Results are not yet entirely satisfactory, but the investigation is being continued. The Ministry of Supply has placed a contract for the design of two types of mobile ground mufflers, one suitable for single-engine aircraft and the other for multiple-engine aircraft. Experiments by a firm of aircraft manufacturers with portable screens, which are placed around the aircraft while the engine is being run up, showed some reduction of noise, and further screens are on order. A firm of consulting engineers is advising four other aircraft manufacturers on the use of specially designed pens for muffing the sound of aircraft the engines of which have to undergo running tests on the ground. Another firm, on its own initiative, is building a pair of mobile ground mufflers to its own design.

Tests being carried out by the Collego of Aeronautics, Cranfield, under Ministry of Supply contract, include the following: the measurement of thrust and noise-levels of engines with nozzles fitted with noise-reduction devices of various designs; the measurement of the sound field from small jets at supersonic speeds, combined with schlieren investigations; and the measurement of the turbulence structure in the mixing region at the jet exit, both at low and high speeds. Laboratory work being carried out at the University of Southampton, which is supported by the Ministry of Supply, includes the development of a shock tube for recording the interaction between an eddy and a shock wave; the 